\title{
27 THE SERVICITIZATION OF PEER PRODUCTION: Reflections on the Open Source Software Experience
}

\author{
Joseph Feller \\ University College Cork, Ireland \\ Patrick Finnegan \\ University College Cork, Ireland \\ Björn Lundell \\ University of Skövde, Sweden \\ Olof Nilsson \\ Mid Sweden University, Sweden
}

The concept of what Yochai Benkler called "peer production" as an alternative mechanism to traditional hierarchies and markets has captured the imagination of numerous communities in contexts ranging from t-shirt design to software to gold mining. While some question the suitability and potential longevity of this mode of production, others are focused on determining ways in which peer-produced products and services can be suitably packaged to meet the requirements of consumers. In particular, the mature peer production phenomenon known as open source software has emerged as a credible alternative to its proprietary counterpart and presents a compelling challenge to both industry and academia as we seek to understand how firms and other organizations can build sustainable business models leveraging the public commons of open source products and the collaborative engine that created them.

This panel will debate how intra- and interorganizational service offerings can be used to create and capture value from peer-produced intellectual property such as open source software. Drawing on their research in the secondary software, software services,

Please use the following format when citing this chapter:

Feller, J., Finnegan, P., Lundell, B., and Nilsson, O., 2008, in IFIP International Federation for Information Processing, Volume 267, Information Technology in the Service Economy: Challenges and Possibilities for the $21^{\text {st }}$ Century, eds. Barrett, M., Davidson, E., Middleton, C., and DeGross, J. (Boston: Springer), pp. 353-355. 
electronic business, and public administration sectors, the panellists will discuss how open source has been used to transform the value offering to consumers and citizens as well as the consequential business model changes for these organizations. In particular, the panelists will discuss the manner in which organizations

- utilize open source frameworks, tools and methods to build systems in an agile, rapid, and economically efficient manner

- build competitive strategies around delivering cocreated services that exploit open source

- $\quad$ adopt open source licensing structures to leverage the power of community-based development, promote particular platforms and standards, grow market- and mindshare, and steward public funds responsibly

In extrapolating from these experiences, the panellists will consider the need for private and public organizations to adopt sophisticated business strategies and models to

- offer services that exploit the various forms of peer-produced intellectual property

- manage the reliance on interorganizational/networked business dynamics

- maintain delicate relationships with peer production communities

The panel will include short position statements by the panellists and a dialogue between them on these positions, followed by a discussion with the audience. Significant time will be allocated to an open discussion with the audience, and those attending are invited to raise their own concerns/opinions in relation to developing service-offerings that exploit peer production.

\section{About the Panelists}

Joseph Feller (JFeller@afis.ucc.ie) is a senior lecturer in Business Information Systems, University College Cork, Ireland. He has written or edited three books on the topic of open source software and has published his research on the topic in a variety of international conferences and journals as well as practitioner publications. His paper (with Brian Fitzgerald), "A Framework Analysis of the Open Source Software Development Paradigm," was awarded Best Paper on Conference Theme at the $21^{\text {st }}$ International Conference on Information Systems. He was program chair for the IEE/ACM workshop series on Open Source Software Engineering (2001-2005), program cochair of the Third International Conference of Open Source Systems, and has been a speaker/panelist on the topic of open source at academic conferences, industry workshops, and European Commission briefings and roundtables. He led, with Finnegan and Lundell, a work package in the EU FP6 CALIBRE project (2004-2006) and is currently a principle investigator in the Open Code, Content and Commerce (03C) Business Models Research Project, funded by the Irish Research Council for the Humanities and Social Sciences.

Patrick Finnegan (P.Finnegan@ucc.ie) received his Ph.D. from the University of Warwick, England, and is currently a senior lecturer in Management Information Systems at University College Cork, Ireland. His research on business models and interorganizational systems has been published in journals including the Information Systems Journal, Information, Technology \& People, Journal of Electronic Commerce, and Electronic Markets. His interest in open source comes from two perspectives: (1) understanding the business models that are required/facilitated by open source, and (2) understanding the effective management of the inter-organisational co- 
operation needed to develop and exploit open source. He led, with Feller and Lundell, a work package in the EU FP6 CALIBRE project (2004-2006) and is currently a principle investigator in the Open Code, Content and Commerce (03C) Business Models Research Project, funded by the Irish Research Council for the Humanities and Social Sciences.

Björn Lundell (bjorn.lundell@his.se) has been a staff member at the University of Skövde, Sweden, since 1984, and has been researching the open source phenomenon for a number of years. He led, with Feller and Finnegan, a work package in the EU FP6 CALIBRE project (2004-2006) and is currently the technical manager in the industrial research project COSI (2005-2008), involving analysis of the adoption of open source practices within companies. His research is reported in a variety of international journals and conferences. He is a founding member of the IFIP Working Group 2.13 on Open Source Software, and the founding chair of Open Source Sweden, an industry association established by Swedish open source companies. He is the organizer of the Fifth International Conference of Open Source Systems (OSS 2009), which is to be held in Skövde, Sweden. In addition, his research has also included fundamental research on evaluation, and associated method support.

Olof Nilsson(O.Nilsson@ucc.ie) is a senior lecturer in Social Informatics at the Mid Sweden University and a Research Fellow at University College Cork, Ireland. His research focuses on access to public information systems, and he has taken an active part in two "triple helix" projects, developing open source applications for public authorities. His research on access has been published in International Journal of Public Information Systems and in a forthcoming edition of International Journal for Humanistic and Social Computing, and also in a number of international conference proceedings. He is currently researching how open source facilitates changes to the traditional approach to public service and government in Sweden. 